\title{
Identification of novel USH2A mutations: implications for the structure of USH2A protein
}

\author{
Bo Dreyer ${ }^{1}$, Lisbeth Tranebjærg ${ }^{1}$, Thomas Rosenberg ${ }^{2}$, Michael D Weston ${ }^{3}$, \\ William J Kimberling ${ }^{3}$ and Øivind Nilssen ${ }^{1}$
}

\begin{abstract}
${ }^{1}$ Department of Medical Genetics, University Hospital and University of Tromsø, Norway; ${ }^{2}$ National Eye Clinic for the Visually Impaired, Hellerup, Denmark; ${ }^{3}$ Department of Genetics, Boystown National Research Hospital, Omaha, NE, USA
\end{abstract}

\begin{abstract}
Usher syndrome type II is an autosomal recessive disorder, characterised by stable hearing impairment from childhood and progressive retinitis pigmentosa from the late teens. Mutations in the USH2A gene, located on 1q41, were recently shown to be responsible for Usher syndrome type lla. We have investigated the molecular pathology of Usher type II by screening the USH2A gene for mutations in 31 unrelated patients from Denmark and Norway. Besides the frequent 2299delG mutation, which accounted for $44 \%$ of the disease alleles, a heterogeneous spectrum of mutations was identified. Sixteen new, putative disease-causing mutations were detected, of which 12 were private and four were shared by unrelated patients. The disease-causing mutations were scattered throughout the gene and included six nonsense and seven missense mutations, two deletions and one small insertion. In addition, six non-pathogenic polymorphisms were identified. All missense mutations resulted in major amino acid side-chain alterations. Four missense mutations affected the N-terminal part of USH2A, whereas three missense mutations affected the laminin-type epidermal growth factor-like (LE) domain. The structural consequences of the mutations affecting the LE domain are discussed in relation to the three-dimensional structure of a LE-module of the mouse laminin $\gamma \mathbf{1}$ chain. European Journal of Human Genetics (2000) 8, 500-506.
\end{abstract}

Keywords: Hearing impairment; retinitis pigmentosa; Usher syndrome type Il; spectrum of mutations; molecular modeling

\section{Introduction}

Usher syndrome (MIM 276900) constitutes a group of autosomal recessive disorders characterised by variable degrees of hearing impairment, vestibular dysfunction and progressive visual loss due to retinitis pigmentosa (RP). The condition is clinically and genetically heterogeneous and is classified into three major subtypes: Usher typel, II and III mapping to any one of nine distinct genetic loci.

Usher typell accounts for morethan half of all Usher cases, with a prevalence of $2.2 / 100000$ in Denmark $^{1}$ and 3.6/100000 in Norway. ${ }^{2}$ Mutations in the USH2A gene, located on 1q41, are responsiblefor Usher syndrome typella. Three deletions were identified in the USH 2A gene, of which 2299delG ${ }^{3,4}$ was found in 29 out of 198 disease alleles (15\%). However, Usher typell is genetically heterogeneous since

Correspondence: Øivind Nilssen, Department of Medical Genetics, University Hospital and University of Tromsø, N-9037 Tromsø, Norway. E-mail: oivindn@fagmed.uit.no

Received 11 November 1999; revised 2 February 2000; accepted

1 March 2000 approximately $12 \%$ of USH 2 families do not show linkage to $1 q 41 .^{5,6}$ Linkage to 3p23-24.2 was recently detected and designated USH2B. ${ }^{6}$

The $\mathrm{N}$-terminal part of the predicted 1546 amino acid residue USH2A protein shares no significant homology with known proteins. However, the deduced protein sequence contains, among others 10 laminin-type epidermal growth factor-like (LE) motifs, each about 50 amino acid residues long and arranged in tandem. The C-terminal part of the protein contains four tandem repeats with similarity to fibronectin typelll elements (FN3). These protein domains are frequently observed in extracellular matrix proteins such as growth factors, receptors and cell adhesion molecules.

We have investigated the molecular pathology of Usher typell patients by screening the USH $2 \mathrm{~A}$ genefor mutations in a panel of 31 Danish and Norwegian patients. Our aim was to identify the classes of mutations which inactivate the USH $2 \mathrm{~A}$ gene or gene product and to investigate the degree of mutational heterogeneity. Such knowledge is essential for patient management and the future design of a rational 
molecular diagnostic strategy for Usher typell patients. Furthermore, the locations and nature of the mutations may contribute to the understanding of the structure and function of the USH2A protein.

\section{Materials and methods Patients}

Altogether 21Danish and 10Norwegian unrelated Usher typell patients were studied. Danish patients were diagnosed at The National Eye Clinic for the Visually Impaired, Hellerup, Denmark. Clinical information about the Norwegian patients was provided by several ophthalmologists and audiol ogists. All patients had stable moderate hearing impairment and sloping audiographs associated with retinitis pigmentosa, verified by ophthalmological and ERG (electroretinogram) examinations. ${ }^{7}$

\section{Mutation detection}

Genomic DNA was isolated from whole blood by use of an automated DNA extractor (341Nucleic Acid Purification System DNA extractor, Applied Biosystems, Foster City, CA, USA) or by salting out methods.

Intronic PCR primers flanking each exon ${ }^{4}$ were used for PCR amplification and direct sequencing. All PCR reactions were carried out on a DNA Thermal Cycler/480, (PerkinElmer, Norwalk, CT, USA). Hot start PCR was performed in a
$30 \mu$ l volume containing: $50 \mathrm{ng}$ genomic DNA, $15 \mathrm{pmol}$ of each primer, $0.2 \mathrm{~mm}$ dNTPs, $1 \times$ GeneAmp PCR buffer II, $1.5 \mathrm{~mm} \mathrm{MgCl}$ and 1.5 unit AmpliTaq ${ }^{\mathrm{TM}}$ DNA polymerase (PE-Biosystems, Branchburg, NJ, USA).

\section{Sequencing and restriction-enzyme analysis}

The PCR products were sequenced with the appropriate primer by the use of PCR-product Presequencing Kit (Amersham Life Science, Buckinghamshire, UK) and ABI PRISM BigDye $^{T M}$ Termination Cycle Sequencing Kit (Perkin-Elmer, PE-Biosystems, Warrington, UK). The sequences were anaIysed on an ABI 377 automated sequencer unit (Perkin-Elmer, Foster City, CA, USA) and mutations were detected by use of associated software and by manual inspection.

For restriction enzyme analysis of the 2299delG deletion, the missense mutations and the polymorphisms, PCR products were digested over night with the appropriate restriction enzyme and analysed by agarose gel electrophoresis. Primer sequences, conditions for PCR and restriction enzymes are listed in Table1.

\section{3-D protein model}

All LE-domains share a common structural element primarily defined by the eight cysteines (PROSIDE document: PDOC00961). The three-dimensional structure of LE domains in mouse $\gamma 1$ chain was used to predict structural

Table 1 Diagnostic PCR methods designed to confirm novel sequence changes or to screen controls

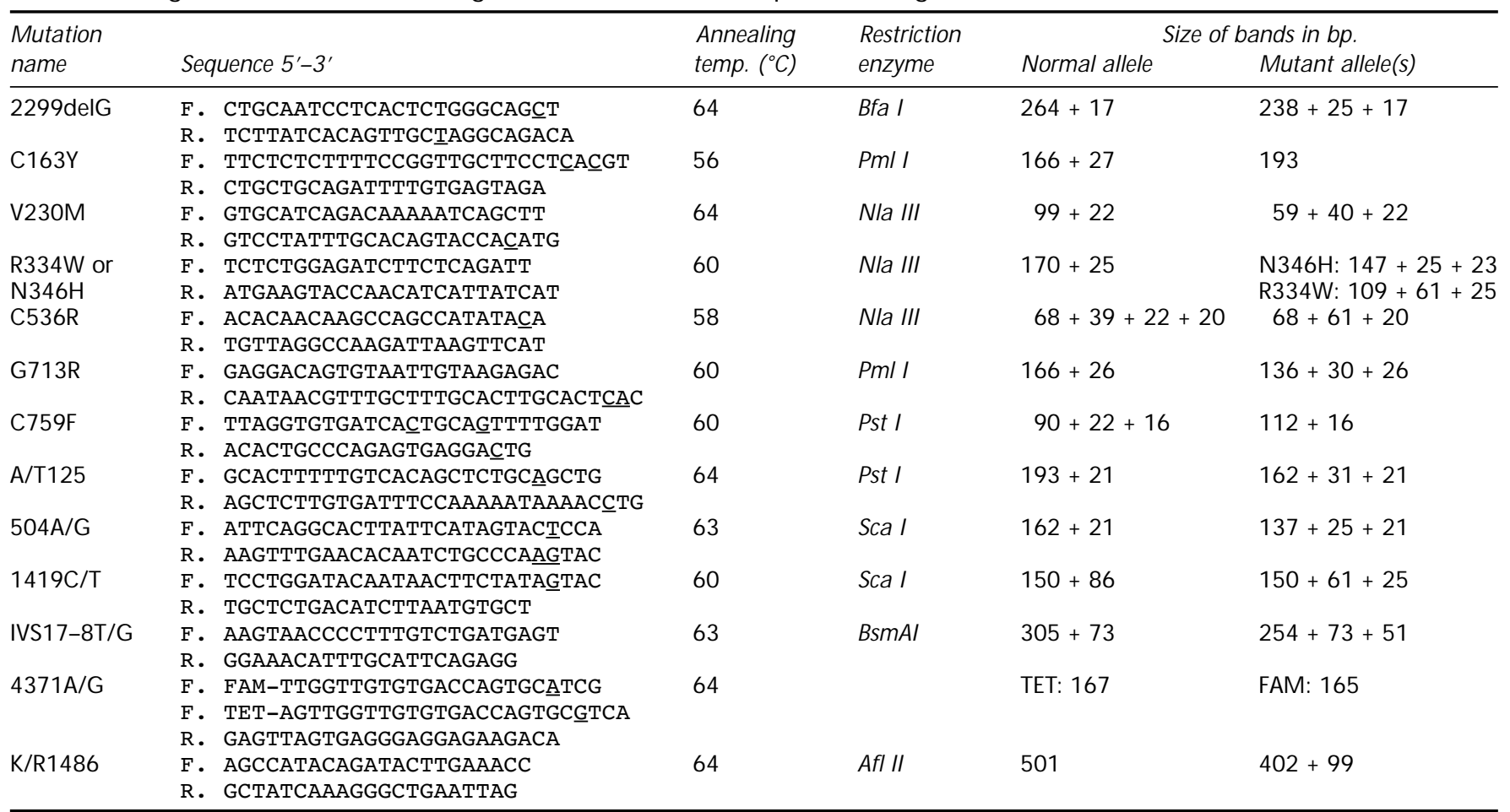

$\mathrm{F}=$ Forward; $\mathrm{R}=$ Reverse; $\mathrm{M}$ ismatches to the genomic sequence are underlined. 
consequences of three missense mutations. The program 'SwissPdBViewer' was used to view the model, PBD entry $1 \mathrm{KLO}^{8}$ and all drawings of the structure were made by use of the program RasM ol v2.6.SWISS MODEL. ${ }^{9}$

\section{Results}

Thirty-one unrelated patients, clinically diagnosed with Usher typell were screened for the 2299delG mutation, ${ }^{3}$ revealing six homozygotes and 12 heterozygotes. Twenty-five patients who were not homozygous for 2299delG, were screened for mutations in the coding region of the USH $2 \mathrm{~A}$ gene. Exon 2 throughout exon 21 were amplified by PCR from genomic DNA and subjected to automated DNA sequencing. Sixteen different putative disease-causing mutations were identified (Table 2 and Figure 1 ). In addition, six polymorphisms not associated with disease were detected (Table3). Disease-alleles were identified in 27 out of 31 patients. Eight patients were homozygotes, 19 were compound heterozygotes, among whom nine disease-alleles remained unidentified (Table4).

\section{Mutations identified}

The mutations, their predicted effect on the USH2A gene and their frequencies are summarized in Tables 2, 3 and 4. Their respective locations within USH2A are indicated in Figure1. The genotypes of the Usher typella patients are listed in Table4.

\section{Nonsense mutations}

Six different mutations leading to premature stop codons were found in six patients, all due to $\mathrm{C} \rightarrow \mathrm{T}$ transitions. Four mutations, resulting in the substitution of arginines for stop codons, were detected at CpG dinucleotides, known to behot spots for transitions. ${ }^{10}$ Two unrel ated Norwegian patients, N1 and N3, had the same mutation at nucleotide100 (R34X). The mutation at nt. 2797 (Q933X) was identified in two unrelated Danish patients, D21 and D7. The transitions at nucleotide positions187, 1876, 2023 and 3883 (R63X, D626X, Q675X and R1295X, respectively) were all private.

\section{Deletions and insertion}

Besides 2299delG, two deletions and one insertion were predicted to lead indirectly to premature stop codons through shift in the translational reading frame. In two unrelated Danish patients, D14 and D15, a 4 bp insertion was identified, which shifts the reading frame after codon 307 ending at a stop codon at position 323. PatientD3 was homozygous for 2878delAA, which results in a frameshift after codon 959 and ending at a UAA stop codon, three residues downstream. Likewise, the 1965delT mutation causes a frameshift after codon 654 introducing an aberrant amino acid sequence that terminates at a UGA stop codon 100 residues downstream.

\section{Missense mutations}

Seven different missense mutations were identified in nine patients. None of the 100 Norwegian control alleles contained the C163Y, N346H, R334W, C536R, G713R or C759F substitutions, whereas the V230M substitution was identified in 1 out of 100 control chromosomes. The $\mathrm{N} 346 \mathrm{H}$ substitution was detected in two unrelated patients, D20 and N7, from Denmark and Norway, respectively. Interestingly, in patientD21, a C163Y replacement as well as two different

Table 2 Summary of disease-causing mutations identified in the USH2A gene

\begin{tabular}{|c|c|c|c|}
\hline Name & Nucleotide change & Location & Effect on coding sequence \\
\hline $\begin{array}{l}\text { Nonsense } \\
\text { R34X } \\
\text { R63X } \\
\text { R626X } \\
\text { Q675X } \\
\text { Q933X } \\
\text { R1295X }\end{array}$ & $\begin{array}{l}100 \mathrm{C} \rightarrow \mathrm{T}^{\mathrm{b}} \\
187 \mathrm{C} \rightarrow \mathrm{T}^{\mathrm{b}} \\
1876 \mathrm{C} \rightarrow \mathrm{T}^{\mathrm{b}} \\
2023 \mathrm{C} \rightarrow \mathrm{T} \\
2797 \mathrm{C} \rightarrow \mathrm{T} \\
3883 \mathrm{C} \rightarrow \mathrm{T}^{\mathrm{b}}\end{array}$ & $\begin{array}{l}\text { EX2 } \\
\text { EX2 } \\
\text { EX11 } \\
\text { EX12 } \\
\text { EX13 } \\
\text { EX18 }\end{array}$ & $\begin{array}{l}\text { Arg } \rightarrow \text { stop at } 34 \\
\text { Arg } \rightarrow \text { stop at } 63 \\
\text { Arg } \rightarrow \text { stop at } 626 \\
\mathrm{Gln} \rightarrow \text { stop at } 675 \\
\mathrm{GIn} \rightarrow \text { stop at } 933 \\
\text { Arg } \rightarrow \text { stop at } 1295\end{array}$ \\
\hline $\begin{array}{l}\text { Deletion or insertion } \\
\text { 921-22insCAGC } \\
\text { 1965delT } \\
\text { 2299delGa } \\
\text { 2878delAA }\end{array}$ & $\begin{array}{l}\text { Insertion of CAGC between } 921 \text { and } 922 \\
\text { Deletion of T at } 1965 \\
\text { Deletion of G at } 2299 \\
\text { Deletion of AA at } 2878\end{array}$ & $\begin{array}{l}\text { EX6 } \\
\text { EX11 } \\
\text { EX13 } \\
\text { EX14 }\end{array}$ & $\begin{array}{l}\text { FS after Ser307, stop at } 323 \\
\text { FS after Leu654, stop at } 755 \\
\text { FS after Ala767, stop at } 787 \\
\text { FS after Val959, stop at } 962\end{array}$ \\
\hline $\begin{array}{c}\text { Missense } \\
\text { C163Y } \\
\text { V230M } \\
\text { R334W } \\
\text { N346H } \\
\text { C536R } \\
\text { G713R } \\
\text { C759F }\end{array}$ & $\begin{array}{l}488 G \rightarrow A \\
688 G \rightarrow A^{b} \\
1000 C \rightarrow T^{b} \\
1036 A \rightarrow C \\
1606 T \rightarrow C \\
2137 G \rightarrow C \\
2276 G \rightarrow T\end{array}$ & $\begin{array}{l}\text { EX3 } \\
\text { EX4 } \\
\text { EX6 } \\
\text { EX6 } \\
\text { EX9 } \\
\text { EX12 } \\
\text { EX13 }\end{array}$ & $\begin{array}{l}\text { Cys } \rightarrow \text { Tyr at } 163 \\
\text { Val } \rightarrow \text { Met at } 230 \\
\text { Arg } \rightarrow \text { Trp at } 334 \\
\text { Asp } \rightarrow \text { His at } 346 \\
\text { Cys } \rightarrow \text { Arg at } 536 \\
\text { Gly } \rightarrow \text { Arg at } 713 \\
\text { Cys } \rightarrow \text { Phe at } 759\end{array}$ \\
\hline
\end{tabular}

Mutation designations correspond to those described by Antonarakis and the Nomenclature Working Group;22 aReported by Weston et al; ${ }^{4}$ bMutation occurs at CpG dinucleotide; FS = frame shift. 


\section{USH2A}

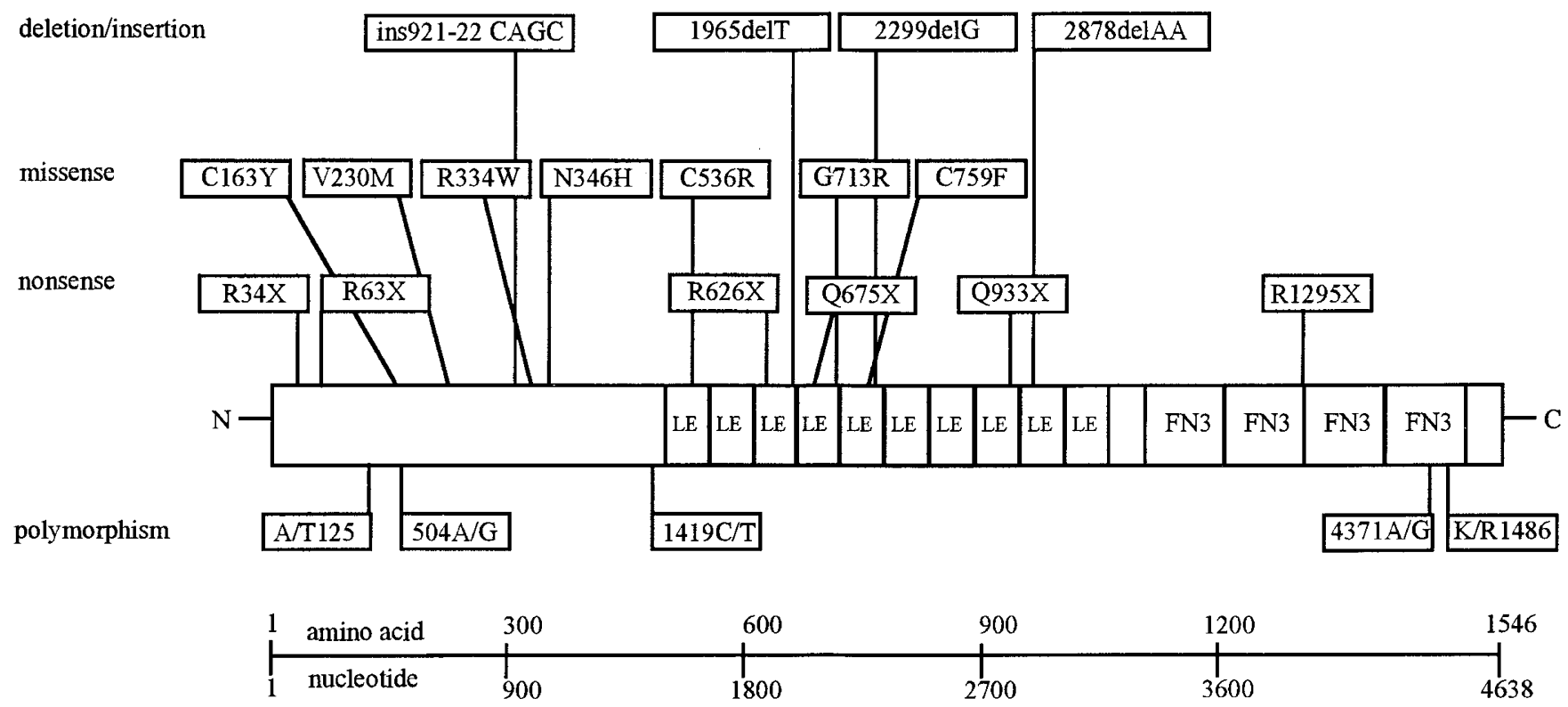

Figure 1 Locations of mutations identified on a schematic presentation of the predicted USH2A protein. Putative functional domains are indicated. All exonic polymorphisms are shown below the diagram; LE = laminin-type EGF-like motif; FN3 = fibronectin type III motif.

nonsense mutations were identified. However, due to lack of DNA from close relatives the cis-trans problem could not be solved. The V230M, R334W, C536R, G713R, and C759F substitutions were all private.

\section{Polymorphisms and unclassified variants}

In addition to the putative disease causing mutations, five exonic and one intronic polymorphism were identified. Three of the exonic mutations were silent (504A/G, 1419C/T and $4371 \mathrm{~A} / \mathrm{G}$ ) and two resulted in amino acid changes (A/T125 and K/R1486). The IVS-8T/G mutation was located in a polypyrimidine tract in close proximity to the acceptor site of intron 8. A similar $\mathrm{T}$ to $\mathrm{G}$ transversion was reported to affect splicing efficiency in the human $\beta$-globin transcript. ${ }^{11}$ However, because of homozygosity in several normal healthy individuals, all six mutations were excluded from being disease-causing. The observed frequencies of these polymorphisms among Norwegian normal chromosomes ranged from 0.03 to 0.36 (Table2). Furthermore, four intronic mutations were observed in several patients. Because, they were presumed to have no effect on RNA-processing they were not tested in the normal control panel but instead regarded as unclassified variants.

Table 3 Polymorphisms and unclassified variants identified in the USH2A gene

\begin{tabular}{|c|c|c|c|c|}
\hline & Nucleotide change & Location & Effect on coding sequence & Frequency among normal chromosomes \\
\hline $\begin{array}{l}\text { Polymorphisms } \\
\text { A/T125 } \\
504 G / A \\
\text { 1419C/T } \\
\text { IVS17-8T/G } \\
\text { 4371A/G } \\
\text { K/R1486 }\end{array}$ & $\begin{array}{l}\text { A or } G \text { at } 125 \\
G \text { or } A \text { at } 504 \\
C \text { or } T \text { at } 1419 \\
\text { T or } G \\
G \text { or } A \text { at } 4371 \\
A \text { or } G \text { at } 4457\end{array}$ & $\begin{array}{l}\text { EX2 } \\
\text { EX3 } \\
\text { EX8 } \\
\text { IVS17 } \\
\text { EX20 } \\
\text { EX21 }\end{array}$ & $\begin{array}{l}\text { Ala or Thr at } 125 \\
\text { Silent } \\
\text { Silent } \\
\text { ND } \\
\text { Silent } \\
\text { Lys or Arg at } 1486\end{array}$ & $\begin{array}{l}70 / 30 \\
72 / 28 \\
62 / 38 \\
77 / 23 \\
97 / 3 \\
64 / 36\end{array}$ \\
\hline $\begin{array}{c}\text { Unclassified varian } \\
\text { IVS3-80T/C } \\
\text { IVS9+34C/A } \\
\text { IVS15+35A/G } \\
\text { IVS18-44A/G }\end{array}$ & $\begin{array}{l}\text { T or C } \\
C \text { or } A \\
A \text { or } G \\
A \text { or } G\end{array}$ & $\begin{array}{l}\text { IVS3 } \\
\text { IVS9 } \\
\text { IVS15 } \\
\text { IVS18 }\end{array}$ & $\begin{array}{l}\text { ND } \\
\text { ND } \\
\text { ND } \\
\text { ND }\end{array}$ & $\begin{array}{l}\text { ND } \\
\text { ND } \\
\text { ND } \\
\text { ND }\end{array}$ \\
\hline
\end{tabular}

$\mathrm{ND}=$ not determined. 
Table 4 Genotypes of the Usher type lla patients

\begin{tabular}{|c|c|c|c|}
\hline Patient/Genotype & Mutation & Mutation & Mutation \\
\hline \multicolumn{4}{|l|}{ Heterozygotes } \\
\hline D8 & 2299delG & ND & \\
\hline D9 & $\mathrm{C} 759 \mathrm{~F}$ & ND & \\
\hline D11 & 2299delG & ND & \\
\hline D12 & 1965delT & ND & \\
\hline D20 & $\mathrm{N} 346 \mathrm{H}$ & ND & \\
\hline D24 & 2299delG & ND & \\
\hline N1 & R34X & ND & \\
\hline N7 & $\mathrm{N} 346 \mathrm{H}$ & ND & \\
\hline N15 & 2299delG & ND & \\
\hline \multicolumn{4}{|c|}{ Compound heterozygotes } \\
\hline D5 & 2299delG & V230M & \\
\hline D7 & 2299delG & Q933X & \\
\hline D10 & 2299delG & R63X & \\
\hline D15 & 2299delG & 921-22insCAGC & \\
\hline D16 & 2299delG & C536R & \\
\hline D17 & 2299delG & G713R & \\
\hline $\mathrm{D} 21^{\mathrm{a}}$ & Q675X & Q933X & $\mathrm{C} 163 \mathrm{Y}$ \\
\hline D23 & 2299delG & $\mathrm{R} 626 \mathrm{X}$ & \\
\hline D25 & 2299delG & R334W & \\
\hline N3 & R34X & R1295X & \\
\hline \multicolumn{4}{|l|}{ Homozygotes } \\
\hline D2 & 2299delG & & \\
\hline D3 & 2878delAA & & \\
\hline D4 & 2299delG & & \\
\hline D14 & 921-22insCAGC & & \\
\hline D18 & 2299delG & & \\
\hline D19 & 2299delG & & \\
\hline N4 & 2299delG & & \\
\hline N5 & 2299delG & & \\
\hline
\end{tabular}

$\mathrm{D}$ and $\mathrm{N}$ indicate Danish and Norwegian origin; ${ }^{\text {ppatient }} \mathrm{D} 21$ : three putative disease-causing mutation were identified. The cis-trans problem could not be solved, due to lack of DNA from close relatives; $\mathrm{ND}=$ not detected.

\section{Discussion}

We have identified pathogenic USH 2A alleles in 27 unrelated Usher typell patients. Putative disease-causing mutations were identified in 45 of the 62 disease alleles studied (73\%). Sixteen new disease-causing mutations were characterised. These included six nonsense, seven missense, two deletions and one insertion. In addition, five exonic and one intronic non-pathogenic polymorphisms were identified.

\section{Characteristics of the mutations}

Since Usher typell is a recessive disorder, the mutations were predicted to be pathogenic due to loss of USH2A function. The nonsense mutations, deletions and insertions leading directly or indirectly to premature termination of translation were predicted to disrupt the function of the USH2A protein. All missense mutations resulted in major changes in the sidechain properties of the corresponding amino acid residue. Regarding the C163Y, V230M, R334W and N346H substitutions, they are all located in the $\mathrm{N}$-terminal part of the protein; however, their disruptive effect on the function of the USH2A protein is not yet known. Among the seven missense mutations reported here, three (C536R, C759F and $\mathrm{G} 713 \mathrm{R}$ ) result in changes of highly conserved residues in the laminin-type epidermal growth factor-like (LE) domain. Hence, Usher typell is caused both by mutations that in homozygous or compound heterozygous states cause complete absence, as well as mutations that cause alterations in single amino acid side chains of the 1546 a.a., USH2A protein.

\section{Structural consequences of the mutations affecting the LE domains}

The availability of the three-dimensional structure of the mouse laminin $\gamma 1$ chain is an important source for predicting the consequences of amino acid substitutions in the LE domains. Based on crystallographic data the LE domains have been shown to be independently folded protein modules. They are described as four looped structures (a-d), stabilised by four disulfide bridges (Figure2). ${ }^{8,12}$ The modules have a distinct variability with respect to the size, structure and arrangement of the loops. The eight invariant cysteine residues principally define the primary structure of the LE domain and form disulfide bonds with the following pattern: Cys1-Cys3 (loop a), Cys2-Cys4 (loop b), Cys5-Cys6 (loop c) and Cys7-Cys9 (loop d) (Figure2). In addition, loop d of the preceding LE module and the loop $b$ of the following LE module form a hook-like association through hydrogen bonds and hydrophobic interactions. ${ }^{8}$ The C536R and C759F substitutions disrupt the disulfide bond formation to C520 (C2) and C747 (C1), respectively (Figure2). Both substitutions were predicted to result in abnormal folding of the LE domain, thereby affecting the functional properties of the protein. The G713R replacement of the hydrophobic side chain of glycine with the positive charged side of arginine, is likely to strongly destabilise the loop structure as suggested by the conservation of the glycine in the multiple alignment (Figure2) The LE domains are thought to function as a rigid, rod-shaped, mechanical spacer that keeps the $\mathrm{N}$-terminal and C-terminal regions apart. ${ }^{12}$ In addition, the LE domains may be involved directly in inter-molecular interactions. Thus, disruption of rigidity as well as disruption of binding properties could explain loss of function of these mutant proteins.

\section{Limitations in mutation detection}

Putative disease-causing mutations were identified in 27 out of $31(87 \%)$ patients studied. In four patients, no alterations were found which could be associated with disease and in nine patients the second disease allele remained unidentified. This relates to general problems in mutation detection such as technical limitations and genetic heterogeneity. Although splice site mutations have been reported to account for $15 \%$ of all mutations involved in human genetic disease, ${ }^{13}$ no putative splice site mutations were observed in this study, despite that all PCR primers were designed to include all exon/intron boundaries. Likewise, in human genetic disease large rearrangements such as deletions and insertions 
A

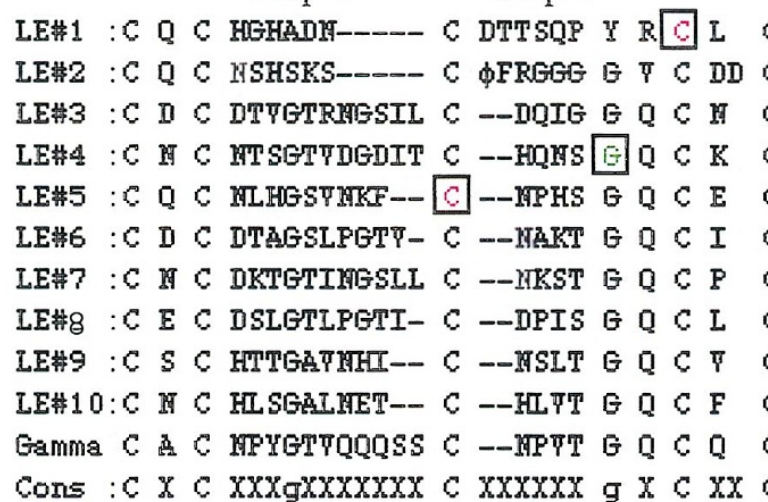

loop c

loop d

$C$ SQESFTE G IH C DR C LPLYMDKPYTYAFY C (523-577)

C EHRTTT-- G RR C EI C KDYFFRQTGAWIDY C (580-643)

C KRHTS-- G RQ C MQ C QYGFYRLQELDPDG C (646-696)

C KARYI-- G LR C IH C FFGFKFLRSFMDTG C (699-749)

C KKEASK-- G LQ C IT C REKFYGLDTTYY--- C (752-797)

C KPYTE-- G RO C HK C LEGMFYLRQMTSFL C (800-849)

C KLGTT-- G LR C MO C EPHRYYLTIDHFOH C (852-902)

$C$ TPYRQD-- G RR C RQ C QPGFYISPGHATG- $C$ (905-953)

$C$ QDASIA- $G$ QR C DO C KDHYFGFDPQTGR- C (956-1004)

C KDFTT-- G SK C DA C TPSASELDTHRLLG C (1007-1054)

C LPFTS-- G RD C GT C DPGYYKLQ--SGQG C (849-897)

$\operatorname{xxXXXXX}$ \& XX $\subset \quad X X \subset \operatorname{xxXXXXXXXXXXXX} \subset$ $\prod_{3}$
$\uparrow_{C 4}^{\uparrow} \uparrow_{C 5}$ $\uparrow \quad \uparrow \quad \uparrow_{C 7}$

$\phi=$ FYYISTDPFPFEH

$x=$ FROGDO

$\psi=\operatorname{DPSA}$

B

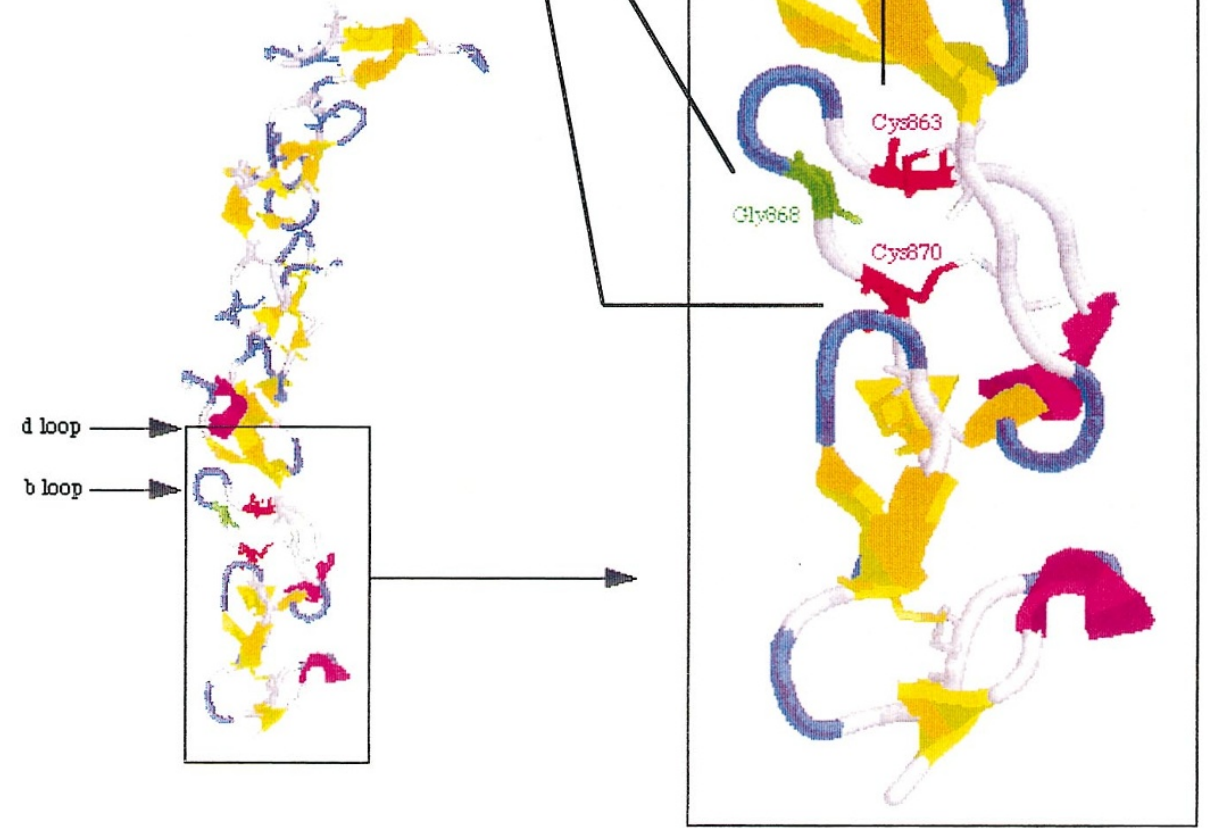

Figure 2 A Alignment A multiple amino acid alignment of the 10 LE (LE No. 1-LE No. 10) domains from the USH2A protein and the third LE domain in mouse laminin $\gamma 1$ chain. The corresponding amino acid residues are in brackets. The position of the cysteine residues (1-8) and conserved glycine residues are aligned, gaps and $\phi, \chi$ and $\psi$ are introduced to show maximal homology. The consensus sequence is the bottom line (Cons). The loop regions are indicated above: loop a (C1-C3), loop b (C2-C4) loop c (C5-C6) and loop d (C7-C8). Residues C536 and C759 are in red, residue G713 is in green. B Structure The three-dimensional structure of the mouse laminin $\gamma$ chain 1 . Strands are yellow, helixes red and turns blue. Loops $d$ and $b$ are indicated by arrows. The side chains involved in substitutions are coloured as in the alignment. Cys863, Gly868 and Cys870 in the mouse laminin $\gamma 1$ chain structure correspond to Cys536, Gly713 and Cys759, respectively in the human USH2A. 
usually account for a large fraction of disease-causing mutations. Southern blot technique will be required to address whether such mutations are involved in USH IIa.

In four patients who met the clinical criteria for Usher typell no USH2A mutations could be identified. One of these patients belong to a previously characterised Norwegian Saami family in which the segregation of 1q41 markers are consistent with the USH2A locus (lod score 3.09). ${ }^{14}$ We cannot exclude the possibility that another Usher locus could be closely linked to the USH 2A locus. As for the remaining three patients linkage to USH2A has not been confirmed.

To date, two genes have been found to be responsible for Usher syndrome. These are MYO7A and USH2A in Usher typel and Usher typell, respectively. So far, 46 mutations likely to be disease-causing have been identified in MY07A and no single mutation appears to predominate, ${ }^{15-20}$ except for a probable founder mutation (C31X) which accounted for $50 \%$ of the mutations in the Danish Usher typel patients. ${ }^{20}$ In Usher typella patients, however, the 2299delG mutation, reported in patients from Scandinavia (Denmark, Norway and Sweden), Northern and Southern Europe, North America, UK and China dominate the mutational spectrum (frequency ranging from 0.15 to 0.44 ). ${ }^{3,21}$

The 2299delG mutation occurs at high and similar frequency among Danish (0.45) and Norwegian (0.42) Usherlla patients. Preliminary results suggest that Danish and Norwegian 2299delG alleles share the same intragenic haplotype based on six SNP markers but deviate with respect to flanking microsatel lite markers (results not shown). Further haplotype analysis is required to determine whether the 2299delG has spread by founder effect and/or recurrent mutational events.

\section{Acknowledgements}

We would like to thank the families for their collaboration and the clinical colleagues who have contributed to this study. We thank Marianne Schwartz, Department of Clinical Genetics, University Hospital, Copenhagen for technical assistance with the Danish patients' samples. This work has been supported by grants from The Norwegian Foundation for Health and Rehabilitation, grant 1998/257 (BD), and The John and Birthe M eyer Foundation (BD, ØN, LT) and by the National Institutes of Health NIDCD grant P01 DC01813-06 and Usher grants from the Foundation Fighting Blindness (W K, MDW).

\section{References}

1 Rosenberg T, Haim M, Hauch AM, Parving A: The prevalence of Usher syndrome and other retinal dystrophy-hearing impairment associations. Clin Genet 1997; 51: 314-321.

2 Grøndahl J: Estimation of prognosis and prevalence of retinitis pigmentosa and Usher syndrome in Norway. Clin Genet 1987; 31: 255-264.
3 Eudy JD, Weston MD, Yao S et al: Mutation of a gene encoding a protein with extracellular matrix motifs in Usher syndrome typella. Science 1988; 280: 1753-1757.

4 Weston MD, Eudy JD, Fujita S et al: Genomic structure and identification of novel mutations in Usherin, the gene responsible for Usher syndrome type IIa. Am J Hum Genet 2000; 66: 1199-1210.

5 Kimberling WJ, Weston MD, Möller C et al: Gene mapping of Usher syndrome typella: localization of the gene to a 2.1-cM segment on chromosomelq41. Am J Hum Genet 1995; 56: 216-223.

6 Hmani M, Ghorbel A, Boulila-Elgaied A et al: A novel locus for Usher syndrome typell, USH2B, maps to chromosome 3 at p23-24.2. Eur J Hum Genet 1999; 7: 363-367.

7 Smith RJ, Berlin Cl, Hejtmancik JF et al: Clinical diagnosis of the Usher syndromes. Usher Syndrome Consortium. Am J Med Genet 1994; 50: 32-38.

8 Stetefeld J, Mayer U, Timpl R, Huber R: Crystal structure of three consecutive laminin-type epidermal growth factor-like (LE) modules of laminin gammal chain harboring the nidogen binding site. J Mol Biol 1996; 257: 644-657.

9 Peitsch MC: ProMod and Swiss-Model: Internet-based tools for automated comparative protein modelling. Biochem Soc Trans 1996; 24: 274-279.

10 Cooper DN, Youssoufian $\mathrm{H}$ : The $\mathrm{CpG}$ dinucleotide and human genetic disease. Hum Genet 1988; 78: 151-155.

11 Sebillon P, Beldjord C, Kaplan JC, Brody E, Marie J: AT to G mutation in the polypyrimidine tract of the second intron of the human beta-globin gene reduces in vitro splicing efficiency: evidence for an increased hnRNP C interaction. Nucleic Acids Res 1995; 23: 3419-3425.

12 Abe Y, Odaka M, Inagaki F, Lax I, Schlessinger J, Kohda D: Disulfide bond structure of human epidermal growth factor receptor. J Biol Chem 1998; 273: 11150-11157.

13 Krawczak M, Reiss J, Cooper DN: The mutational spectrum of single base-pair substitutions in mRNA splice junctions of human genes: causes and consequences. Hum Genet 1992; 90: 41-54.

14 Fagerheim T, Raeymaekers P, Merren J et al: Homozygosity mapping to the USH2A locus in two isolated populations. J Med Genet 1999; 36: 144-147.

15 Weil D, Blanchard S, Kaplan J et al: Defective myosin VIIA gene responsible for Usher syndrome type1B. Nature 1995; 374: 60-61.

16 Weston MD, Kelley PM, Overbeck LD et al: Myosin VIIA mutation screening in 189 Usher syndrome type 1 patients. Am J Hum Genet 1996; 59: 1074-1083.

17 Adato A, Weil D, Kalinski $\mathrm{H}$ et al: Mutation profile of all 49 exons of the human myosin VIIA gene, and haplotype analysis, in Usher 1B families from diverse origins. Am J Hum Genet 1997; 61: 813-821.

18 Levy G, Levi Acobas F, Blanchard S et al: Myosin VIIA gene: heterogeneity of the mutations responsible for Usher syndrome typelB. Hum Mol Genet 1997; 6: 111-116.

19 Liu XZ, Newton VE, Steel KP, Brown SD: Identification of a new mutation of the myosin VII head region in Usher syndrome type1. Hum Mutat 1997; 10: 168-170.

20 Janecke AR, Meins $M$, Sadeghi $M$ et al: Twelve novel myosin VIIA mutations in 34 patients with Usher syndrome typel: confirmation of genetic heterogeneity. Hum Mutat 1999; 13: 133-140.

21 Liu XZ, Hope C, Liang CY, et al: A Mutation (2314delG) in the Usher Syndrome TypellA Gene: High Prevalence and Phenotypic Variation. Am J Hum Genet 1999; 64: 1221-1225.

22 Antonarakis SE: Recommendations for a nomenclature system for human gene mutations. Nomenclature Working Group. Hum Mutat 1998; 11: 1-3. 